\title{
Omalizumab in pregnant women treated due to severe asthma: two case reports of good outcomes of pregnancies
}

\author{
Izabela Kupryś-Lipińska, Damian Tworek, Piotr Kuna
}

Department of Internal Medicine, Asthma and Allergy, Norbert Barlicki Memorial University Hospital No 1 in Lodz, Medical University of Lodz, Poland

Head of Department: Prof. Piotr Kuna MD, PhD

Postep Derm Alergol 2014; XXXI, 2: 104-107 DOI: $10.5114 /$ pdia.2014.40975

\begin{abstract}
The article presents case reports of 2 women who became pregnant during therapy with omalizumab. Both subjects suffered from very severe asthma and were treated chronically with all available medications including systemic steroids (first - $20 \mathrm{mg}$ prednisolone/day, second $-40 \mathrm{mg}$ prednisolone/day). Both were enrolled into treatment with omalizumab and started regular therapy in 2007. The course of asthma significantly improved in both cases (withdrawal of oral steroids or significant reduction of their dose, better asthma control). The first woman, 32-year-old, became pregnant in 2010 and gave birth in Oct 2010 - it was her $3^{\text {rd }}$ pregnancy, and $3^{\text {rd }}$ labor. The second woman, 31-year-old, also became pregnant in 2010 and gave birth in Jan 2011 - it was her $5^{\text {th }}$ pregnancy and $2^{\text {nd }}$ labor. Both had severe asthma exacerbations during previous pregnancies and labors, and decided to continue therapy with omalizumab. The first woman, besides omalizumab, was treated with high doses of inhaled corticosteroids (ICS) and long-acting $\beta$ agonists (LABA) while the second one was treated with high doses of ICS, LABA and $2.5 \mathrm{mg}$ to $5 \mathrm{mg}$ prednisone/day. The pregnancies proceeded without asthma exacerbations. The first woman delivered a healthy girl (Apgar 9, weight $3200 \mathrm{~g}$, length $56 \mathrm{~cm}$ ) in the $40^{\text {th }}$ week of pregnancy by caesarean section due to the narrow pelvis. The second one delivered a healthy boy (Apgar 9, weight $3800 \mathrm{~g}$, length $56 \mathrm{~cm}$ ) in week 40 by caesarean section due to the aggravating obstetrical history. In both cases, treatment with omalizumab did not affect pregnancies and newborns.
\end{abstract}

Key words: severe asthma, pregnancy, omalizumab.

\section{Introduction}

Asthma is one of the most common chronic conditions that occur in the pregnant woman [1]. The prevalence of asthma during pregnancy is estimated to be $3.7-8.4 \%$ [2]. There is some evidence from epidemiological studies that asthma increases the risk of preterm birth, intrauterine grown restriction, low birth weight, preeclampsia, congenital malformations and other pregnancy and labor complications [3-10]. Whether asthma or medications have an influence on the pregnancy and conditions of the fetus is the subject of many observational studies. There is unquestionable evidence that uncontrolled asthma is associated with the increased risk for the mother and the unborn child [11-13]. The perinatal prognosis for the children born to women with well-controlled asthma is the same as for women with- out asthma $[14,15]$. Therefore, optimization of asthma treatment during pregnancy is vital to achieve good outcomes. However, physicians and their patients may have some doubts about the safety of anti-asthmatic drugs, especially new ones.

Omalizumab is a humanized recombinant anti-lgE monoclonal antibody class $G$ recommended for the treatment of chronic severe IgE-mediated asthma [16]. Clinical and observational studies have confirmed its effectiveness in improving asthma control, reducing severe exacerbations and improving the quality of life [17-20]. IgG molecules are known to cross the placental barrier [21-23] and are excreted to the milk [24]. Data about the safety of omalizumab during pregnancy and lactation comes from experimental studies on animals; no embryotoxic and teratogenic effect has been found when omalizumab is administered throughout organogenesis

Address for correspondence: Izabela Kupryś-Lipińska MD, PhD, Department of Internal Medicine, Asthma and Allergy, Norbert Barlicki Memorial University Hospital No 1 in Lodz, Medical University of Lodz, 22 Kopcinskiego St, 90-153 Lodz, Poland, phone: +48 606 819702 , fax: +48 4267811 76, e-mail: izabela.kuprys-lipinska@umed.lodz.pl Received: 7.01.2014, accepted: 14.01.2014. 
and it was not seen to elicit adverse effects on fetal or neonatal growth when administered throughout late gestation, delivery and nursing [25].

This study presents case reports of 2 women who became pregnant during treatment with omalizumab: both cases had very severe asthma which was continuously treated with all available medications including systemic steroids (first - $20 \mathrm{mg}$ prednisolone/day, second - $40 \mathrm{mg}$ prednisolone/day). Both started their regular treatment with omalizumab in 2007 and demonstrated significant improvement (withdrawal of oral steroids or significant reduction of their dose, better asthma control).

\section{Case reports}

\section{Case 1}

The first subject was a 32-year-old woman with a history of asthma since the age of 15 years. She had suffered from severe steroid-dependent asthma since she was 22 years old. Symptoms of allergy to house dust mites were confirmed by skin prick tests. Up to 2007, frequent asthma exacerbations were experienced due to exposure to allergens and during airway infections. Her lung function has been progressively impaired. She was treated with methylprednisolone 16 mg/day, fluticasone 2000 mg/day and formoterol $48 \mathrm{mg} /$ day. Omalizumab (OMA) therapy was introduced in 2006. The dose of omalizumab-600 mg/ month - was calculated based on a total IgE value of $403 \mathrm{lU} /$ $\mathrm{ml}$ and a body weight of $55 \mathrm{~kg}$.

Clinical improvement with a reduction in oral glucocorticosteroids (OCS) was obtained, but therapy was interrupted after 3 months due to the problems with reimbursement. Anti-lgE therapy was continued with some breaks since its reintroduction in 2007. During the treatment, the asthma was seen to become aggravated by a break longer than 2 months. Currently, the patient is treated with fluticasone $500 \mathrm{mg} /$ day and formoterol $24 \mathrm{mg} /$ day without systemic steroids. Since 2007, she has had one severe asthma exacerbation.

The subject has given birth to 3 girls. The first pregnancy was in 1998 when her asthma was mild and she was treated during the pregnancy with budesonide and salbutamol. No asthma exacerbation occurred during pregnancy and a healthy girl (Apgar 9, weight $3700 \mathrm{~g}$, length $55 \mathrm{~cm}$ ) was delivered at 39 weeks' gestation by caesarean section due to a narrow pelvis. Her second pregnancy occurred in 2000. This time, her asthma was more severe, with one severe asthma exacerbation during pregnancy, and so was treated with a regime of budesonide and salbutamol. Nevertheless, a healthy girl (Apgar 8, weight 3700 g, length $54 \mathrm{~cm}$ ) was successfully delivered at 40 weeks' gestation by caesarean section due to a narrow pelvis.

In 2010, in the $3^{\text {rd }}$ year of omalizumab therapy, she became pregnant for the third time. Beside the omalizumab, the treatment regime comprised fluticasone, formoterol and salbutamol. During the pregnancy she ex- perienced one lower airway infection, which was treated by antibiotics without asthma exacerbation. A healthy girl (Apgar 9, weight $3300 \mathrm{~g}$, length $55 \mathrm{~cm}$ ) was delivered after 39 weeks' gestation by caesarean section due to a narrow pelvis. All children are healthy, and have shown no symptoms of allergic diseases up to today. All were breastfed during first weeks of life, but the third child was breastfed for one month only, due to insufficient lactation.

\section{Case 2}

The second woman was 31-year-old. Her asthma history started at 15 years at which age a severe steroid-dependent course was required. Allergies to house dust mites and tree pollen were presented, which were confirmed by skin prick tests. Exposure to allergens and airway infections were found to be associated with her frequent severe asthma exacerbations. Her lung function was not permanently impaired, but was much reduced during severe exacerbations.

She was treated with prednisone $40 \mathrm{mg} / \mathrm{day}$, fluticasone 1000 mg/day, formoterol 48 mg/day before omalizumab therapy was introduced in 2006. The adjusted omalizumab dose was $150 \mathrm{mg} / \mathrm{month}$, calculated based on a total lgE concentration of $93 \mathrm{lU} / \mathrm{ml}$ and a body weight of $45 \mathrm{~kg}$. Clinical improvement prompted a reduction of the OCS dose, but the therapy had to be interrupted due to the problems with reimbursement and was reintroduced in 2007. Since that time, anti-lgE therapy has been almost regularly continued. A treatment time interval longer than 2 months resulted in asthma aggravation. Currently, the patient is being treated with a regime of budesonide/formoterol 320/9 mg BID, prednisone $10 \mathrm{mg}$. Only two severe asthma exacerbations have been noted since 2007.

Her obstetrical history is aggravating. Her $1^{\text {st }}$ pregnancy in 2000 terminated with spontaneous abortion. At that time, the course of asthma was severe and uncontrolled and she was treated with budesonide, formoterol, prednisone and salbutamol. The second pregnancy occurred in 2002, when her asthma during the pregnancy was severe and uncontrolled, and she was treated with budesonide, formoterol, up to $40 \mathrm{mg}$ /day prednisone, and salbutamol as needed. Frequent, severe asthma exacerbations were experienced during pregnancy: asthmaticus status also occurred during labor. The intrauterine growth restriction of the fetus and imminent preterm birth were the complications of the severe uncontrolled course of the disease. She delivered a boy (Apgar 9, weight 2800 g, length $54 \mathrm{~cm}$ ) at 38/39 weeks' gestation by caesarean section due to the asthmaticus status.

The third pregnancy occurred in 2006, but finished with spontaneous abortus in the $8^{\text {th }}$ week. The severe uncontrolled asthma was treated with budesonide, formoterol, prednisone up to $40 \mathrm{mg} /$ day and salbutamol as needed. In 2009, the next pregnancy occurred in the $2^{\text {nd }}$ 
year of biological therapy, but resulted in her $3^{\text {rd }}$ spontaneous abortus in the $6^{\text {th }}$ week. During the pregnancy, her asthma was controlled by omalizumab, budesonide, formoterol, prednisone $10 \mathrm{mg} /$ day and salbutamol therapy.

In 2011, during the $5^{\text {th }}$ pregnancy, the asthma was treated with omalizumab, budesonide, formoterol, prednisone $5 \mathrm{mg} /$ day to $2.5 \mathrm{mg} /$ day and salbutamol and was well controlled. No asthma exacerbation occurred during the pregnancy, although she was hospitalized due to the urine tract infection and the risk of imminent preterm birth. She delivered a boy (Apgar 9, weight 3800 g, length $56 \mathrm{~cm}$ ) at 40 weeks' gestation by caesarean section due to the aggravating obstetrical history. The boy was born with an intrauterine infection diagnosed as a congenital pneumonia (abnormal X-ray, increasing C-reactive protein). His mother had a urine tract infection during labor. Besides he was in a good clinical condition, he was treated successfully with antibiotics (ampicillin, gentamicin) and discharged from hospital on the $7^{\text {th }}$ day of life. In the $6^{\text {th }}$ week of life he was hospitalized due to an Respiratory syncytial virus infection, probably was infected by his older brother. Both boys have suffered from severe asthma and had been fed with hypoallergenic infant formula since the birth.

\section{Discussion}

Although the use of any drugs during pregnancy, especially in the 1st trimester, can cause concern [26], there is a body of evidence that severe uncontrolled asthma during the pregnancy represents a serious risk for both the mother and the child [10-12]. Therefore, the aim of asthma treatment during the pregnancy is optimal control [27, 28]. Both inhaled and oral antiasthmatic drugs are generally considered as safe: only OCS and theophylline may have some negative effects. The view of GINA is that using medication to control asthma is justified, even if its use during pregnancy has not been unequivocally proven to be safe [26].

The European Medicines Agency statement is that omalizumab should not be used during pregnancy unless clearly necessary [29]. The US Food and Drug Administration has classified omalizumab as a category B drug with regard to safety during pregnancy, together with budesonide, fenoterol, ipratropium, cromoglycate, nedocromil and montelukast. This rating is higher than that of beclomethasone, fluticasone, formoterol, salbutamol, salmeterol, theophylline and tiotropium, but the prescribing information contains still a warning that omalizumab should be used during pregnancy only if clearly needed [30].

Only two case reports concerning omalizumab usage in pregnant woman was published: one in an abstract in 2011 [31], and the other in a Japanese journal in 2012 [32]. The first case was a 35-year-old Brazilian woman successfully treated with omalizumab due to severe uncontrolled asthma who become pregnant in 2010 and delivered a healthy child. She had a previous aggravating obstetrical history, with fetal death in the $8^{\text {th }}$ month of pregnancy as a complication of severe uncontrolled asthma. The other case was a 38-year-old Japanese woman with severe asthma treated for a long time with oral steroids. She had aggravating obstetrical history 6 spontaneous abortions due to asthma exacerbation and one healthy child. She received omalizumab shortly before pregnancy and initially continued but subsequently interrupted the therapy not feeling improvement. She experienced one severe asthma exacerbation during the pregnancy due to the common cold. At 26 weeks' gestation due to the threat of abortion, a cesarean section was performed and she delivered a 544-g female baby. The child had to be hospitalized in the neonatal intensive care unit because of low birth weight, but she has been developing and growing without handicap. In these two cases no embryotoxic and teratogenic effect was observed, the same as in our patients. The preterm labor in the Japanese case should be referred to uncontrolled asthma and severe exacerbation. The intrauterine infection in our second patient was due to the patient condition, but the child was healthy, and standard treatment was effective.

A registry of pregnant women exposed to omalizumab in real life circumstances is being drawn up in the USA and first data from 250 women were presented at the American Thoracic Society Congress in 2012. No risk related to omalizumab has been detected up to now [33].

Even if omalizumab treatment is stopped due to pregnancy, the exposure to the drug is continued due to the drug kinetics - its serum elimination half-life averaged 26 days. Therefore, the drug persists for much longer in serum than the time of treatment. Thus, it seems reasonable that omalizumab should not be withheld due to the pregnancy, partly because the risk of the asthma deterioration is higher than the potential risk to the fetus, and partly because the exposure will not be completely prevented anyway.

\section{Conclusions}

In both cases, treatment with omalizumab was found to be an effective therapy which improved asthma control, protected patients from exacerbations and enabled reduction of oral steroid doses. Omalizumab did not adversely affect pregnancies and newborns.

The decision to continue or discontinue anti-lgE therapy should always be made on a case-by-case basis, carefully taking into consideration the balance between the estimated benefits and potential risks.

In every case, the consent of the pregnant woman must be obtained after providing her with detailed information about potential risks imposed by the therapy.

\section{Conflict of interest}

Dr Izabela Kupryś-Lipińska - honoraria for lectures from Novartis. Dr Damian Tworek - no conflict of interest. Prof Piotr Kuna - honoraria for lectures from Novartis. 


\section{References}

1. National Heart, Lung, and Blood Institute. National Asthma Education and Prevention Program. NAEPP expert panel report. Managing asthma during pregnancy: recommendations for pharmacologic treatment - 2004 update. J Allergy Clin Immunol 2005; 115: 34-46.

2. Kwon HL, Belanger K, Bracken MB. Asthma prevalence among pregnant and childbearing-aged women in the United States: estimates from national health surveys. Ann Epidemiol 2003; 13: 317-24.

3. Demissie K, Breckenridge MB, Rhoads GG. Infant and maternal outcomes in the pregnancies of asthmatic women. Am J Respir Crit Care Med 1998; 158: 1091-5.

4. Liu S, Wen SW, Demissie K, et al. Maternal asthma and pregnancy outcomes: a retrospective cohort study. Am J Obstet Gynecol 2001; 184: 90-6.

5. Kallen B, Rydhstroem H, Aberg A. Asthma during pregnancy: a population based study. Eur J Epidemiol 2000; 16: 167-71.

6. Schatz M, Zeiger RS, Hoffman CP, et al. Perinatal outcomes in the pregnancies of asthmatic women: a prospective controlled analysis. Am J Respir Crit Care Med 1995; 151: 1170-4.

7. Liu S, Wen SW, Demissie K, et al. Maternal asthma and pregnancy outcomes: a retrospective cohort study. Am J Obstet Gynecol 2001; 184: 90-6.

8. Enriquez R, Griffin MR, Carroll KN, et al. Effect of maternal asthma and asthma control on pregnancy and perinatal outcomes. J Allergy Clin Immunol 2007; 120: 625-30.

9. Murphy VE, Namazy JA, Powell H, et al. A meta-analysis of adverse perinatal outcomes in women with asthma. BJOG 2011; 118: 1314-23.

10. Blais L, Kettani FZ, Forget A. Relationship between maternal asthma, its severity and control and abortion. Hum Reprod 2013; 28: 908-15.

11. Bakhireva LN, Schatz M, Jones KL, Chambers CD; Organization of Teratology Information Specialists Collaborative Research Group. Asthma control during pregnancy and the risk of preterm delivery or impaired fetal growth. Ann Allergy Asthma Immunol 2008; 101: 137-43.

12. O'Byrne PM, Pedersen S, Schatz M, et al. The poorly explored impact of uncontrolled asthma. Chest 2013; 143: 511-23.

13. Namazy JA, Murphy VE, Powell H, et al. Effects of asthma severity, exacerbations and oral corticosteroids on perinatal outcomes. Eur Respir J 2013; 41: 1082-90.

14. Stenius-Aarniala B, Piirila P, Teramo K. Asthma and pregnancy: a prospective study of 198 pregnancies. Thorax 1988; 43: 12-8.

15. Schatz M, Zeiger RS, Hoffman CP, et al. Perinatal outcomes in the pregnancies of asthmatic women: a prospective controlled analysis. Am J Respir Crit Care Med 1995; 151: 1170-4.

16. Hamelmann E. The rationale for treating allergic asthma with anti-lgE. Eur Respir Rev 2007; 16: 61-6.

17. Kupczyk M, Kuna P. Omalizumab in an allergology clinic: real life experience and future developments. Postep Derm Alergol 2014; 31: 32-5.

18. Kupryś-Lipińska I, Korczyńska P, Tworek D, Kuna P. Effectiveness of omalizumab in a patient with a life-threatening episode of bronchospasm and larynx angioedema after exposure to house dust. Postep Derm Alergol 2014, 31: 39-44.

19. Jerzyńska J, Sztabińska A, Woicka-Kolejwa K, Stelmach I. Omalizumab as a new therapeutic approach for children with severe asthma. Postep Derm Alergol 2014; 31: 45-6.

20. Skiepko R, Zietkowski Z, Skierko U, et al. Omalizumab treatment in brittle asthma. Postep Derm Alergol 2014; 31: 36-8.
21. Malek A, Sager R, Schneider H. Maternal-fetal transport of immunoglobulin $\mathrm{G}$ and its subclasses during the third trimester of human pregnancy. Am J Reprod Immunol 1994; 32: 8-14.

22. Malek A, Sager R, Kuhn P, et al. Evolution of maternofetal transport of immunoglobulins during human pregnancy. Am J Reprod Immunol 1996; 36: 248-55.

23. Ben-Hur H, Gurevich P, Elhayany A, et al. Transport of maternal immunoglobulins through the human placental barrier in normal pregnancy and during inflammation. Int J Mol Med 2005; 16: 401-7.

24. Watson DL. Immunological functions of the mammary gland and its secretion: comparative review. Aust J Biol Sci 1980; 33: 403-22.

25. Prescribing information Xolair Novartis Pharmaceuticals.

26. Zetstra-van der Woude PA, Vroegop JS, Bos HJ, de Jong-van den Berg LT. A population analysis of prescriptions for asthma medications during pregnancy. J Allergy Clin Immunol 2013; 131: 711-7.

27. GINA Report, Global Strategy for Asthma Management and Prevention Updated December 2012. www.ginasthma.org

28. Expert Panel Report 3 (EPR-3): Guidelines for the Diagnosis and Management of Asthma-Summary Report 2007.National Asthma Education and Prevention Program. J Allergy Clin Immunol 2007; 120 (5 Suppl): S94-138.

29. http://www.ema.europa.eu/ema/

30. www.fda.gov

31. Emerson F, Cordeiro N, Rocha MV, et al. Fetal loss in severe asthma and posterior healthy pregnancy and birth with the use of omalizumab - case report. https://wao.confex.com/ wao/2011wac/webprogram/Paper4252.html

32. Hirashima J, Hojo M, likura M, et al. A case of an asthma patient receiving omalizumab during pregnancy. Arerugi 2012; 61: 1683-7.

33. Namazy J, Cabana MD, Scheuerle A, et al. The Xolair pregnancy registry (expect): an observational sudy of the safety of omalizumab during pregnancy in women with asthma. Am J Respir Crit Care Med 185; 2012: A4221. 